\title{
Nexos de Significado: algumas considerações linguísticas sobre uma aplicação do Miniexame do Estado Mental
}

\author{
Links of meaning: some linguistic considerations on an application of the Mini Mental State Examination
}

\section{Heronides Moura \\ Denise Dias Martins}

Universidade Federal de Santa Catarina - UFSC - Florianópolis - Santa Catarina - Brasil

\begin{abstract}
$\longrightarrow$
Resumo:Neste artigo, pretende-se mostrar que a Linguística Cognitiva pode fornecer instrumentos que permitam uma análise mais fina dos resultados da aplicação do Miniexame do Estado Mental, que é utilizado clinicamente como um auxílio para o diagnóstico da Demência de Alzheimer. Será analisada, em primeiro lugar, a estrutura de uma frase citada por uma paciente, na aplicação do exame. A seguir, será abordada a troca de palavras por uma paciente, buscando-se demonstrar o quanto a mudança foi significativa do ponto de vista cognitivo e não, simplesmente, um erro.
\end{abstract}

Palavras-chave:Linguística Cognitiva. Predicação.Frames.

\begin{abstract}
The aim of this article is to show that Cognitive Linguistics can provide the tools for a more fine-grained analysis of the results of the Mini Mental State Examination, which is used by clinicians to help diagnose Alzheimer dementia. First, it will be considered the structure of a sentence said by a patient, in an application of the test. Secondly, it will be examined the change of words performed by a patient. We try to show that this change was meaningful, from a cognitive point of view and not a simple error.
\end{abstract}

Keywords: Cognitive Linguistics. Predication. Frames.

\section{Introdução}

A motivação para escrever este trabalho surgiu em uma aula de pós-graduação em que era discutida a questão da Demência de Alzheimer.

Numa turmacomposta de linguistas, fonoaudiólogos e pedagogos, surgiram dúvidas, vários questionamentos e ponderações sobre se o que tinha sido produzido por uma paciente, em resposta a um teste (o Miniexame do Estado Mental) que avaliava a linguagem dela, era uma frase ou não. Isso demonstra o quanto alguns conceitos e nomenclaturas gramaticais ou não estão bem claros ou o que significam não é consenso. Disso surgiu a necessidade de se explorar e discutir a resposta dessa paciente. Além dessa questão, outra resposta suscitou algumas discussões: quando a paciente deveria lembrar-se das palavras "carro", "tijolo" e "vaso", ela trocou a palavra "tijolo" por "muro". Esse ponto também chamou a atenção da turma, que reparou que um muro é feito de tijolos. Esse trabalho pretende discutir essas duas respostas à luz de algumas teorias linguísticas e demonstrar que esses "erros" não seriam aleatórios.

Primeiramente, serão examinados alguns conceitos da gramática tradicional, considerando que o conceito e a nomenclatura "frase" são filiados a ela. Em seguida, a estrutura da "frase" apresentada pela paciente é discutida a partir de algumas teorias 
linguísticas. A seguir, será abordada a troca de palavras evocadas pela paciente, buscando-se demonstrar o quanto a mudança foi significativa e não, simplesmente, um erro.

\section{0 que é uma frase?}

\subsection{A nomenclatura da gramática normativa}

\section{Os Parâmetros Curriculares Nacionais} aconselham parcimônia no uso e ensino da metalinguagem gramatical aos alunos, e indicam que ela deve emergir e ser selecionada a partir da produção escrita dos alunos. Além disso, algumas Teorias da Enunciação e de Análise do Discurso têm permeado 0 ensino da gramática nas escolas (BRASIL, 1997). Todavia, ao se examinar o sumário de um livro do 5ํano de Ensino Fundamental que está sendo oferecido neste ano (2014) pelo Programa Nacional de Livros Didáticos, do Ministério da Educação - a saber, Projeto Prosa, de Angélica Prado e Cristina Hülle, da editora FTD, publicado em 2011 -, percebe-se que a gramática tradicional, com suas nomenclaturas, continua a ser ensinada nas escolas.

Dessa forma, e tendo-se em vista que o que é solicitado no teste é uma "frase", que é um conceito gramatical, nesta seção será discutido como esse conceito se estabelece na gramática tradicional, para depois analisá-lo sob o prisma de algumas teorias linguísticas.

O Miniexame do Estado Mental é um dos instrumentos usados para um possível diagnóstico da Demência de Alzheimer. Ele, em tese, indica se o paciente está tendo perdas cognitivas e deve passar por exames mais complexos e dispendiosos. $\mathrm{Na}$ seção Linguagem, questão 9 , solicita-se que o paciente escreva "alguma coisa com começo, meio e fim. O que a senhora quiser, um pensamento, alguma coisa que aconteceu hoje. Alguma coisa que tenha começo, meio e fim". (CRUZ, 2004, p. 192). Então a pacienteproduz:

(1) Amar a Deus
O avaliador esperava que ela produzisse uma frase: "Ela perdeu mais um ponto pela frase, porque escreveu "Amar a Deus" que não é uma frase". (CRUZ, 2004, p. 192). Analisando segundo a gramática normativa, o que a paciente produziu não é uma frase, se considerarmos que "frase" é uma "oração", tendo em vista que Bechara (2003, p. 540) diferencia:

[...] a unidade sintática chamada oração constitui o centro da atenção da gramática por se tratar de uma unidade onde se relacionam sintaticamente seus termos constituintes e onde se manifestam as relações de ordem e recção que partem do núcleo verbal e das quais se ocupa a descrição gramatical. Isto não impede a presença de enunciados destituídos desse núcleo verbal conhecidos pelo nome de frases: Bom dia! Saúde! Depressa! Que calor!

O autor explica que essas frases são proferidas em situações em que o enunciado não se manifesta em toda sua plenitude, "o enunciado também aparece sob forma de frase, cuja estrutura interna difere da oração porque não apresenta relação predicativa”. (BECHARA, 2003, p. 407).

Além disso, Bechara acrescenta que podem ocorrer frases sem núcleo verbal resultantes de respostas ou comentários a diálogos.

São frases elípticas, quase sempre de valor nominal, resíduos de orações sintaticamente incompletas ou truncadas, que devem ser tratadas no rol dos enunciados independentes sem núcleo verbal, ao largo de qualquer restituição corretiva do ponto de vista sintático: - Está bem, deixe-me ficar algum tempo mais, estou na pista de um mistério... Que mistério? [...] - Raposo, vou sair; há alguma coisa? Nada, Capitão Viveiros. (BECHARA, 2003, p. 541).

Pode-se pensar em um diálogo no qual alguém perguntasse para a paciente: - Oque é mais importante para a senhora? E ela responderia: Amar a Deus. Neste contexto, conforme a explicação do professor Bechara, a resposta dela seria indubitavelmente uma frase.

Já a oração é um conceito sintático muitas vezes confundido com frase. Na oração, o verbo é a 
palavra fundamental e a relação de predicação se estabelece no entorno dele, entre o sujeito e seus objetos, se houver, no caso de o verbo ser transitivo. Esse verbo deve ser finito, isto é, conjugado, e aqui não se pode considerar como conjugação o particípio (por exemplo, estudado, feito, que são formas nominais adjetivas) e o gerúndio (fazendo, digitando, usado em locuções verbais ou orações subordinadas) por serem formas nominais, bem como o infinitivo (correr, escrever, usado em subordinadas e considerado o nome do verbo).

As formas nominais dos verbos, infinitivo, gerúndio e particípio, não formam orações independentes, justamente porque, como foi explicado, não veiculam a relação da predicação. Essas formas geralmente entram na composição de sentenças subordinadas. Podemos fazer um exercício de composição de orações com a resposta da paciente, que é o que está sendo solicitado a ela com o título de frase, já que existe a exigência de sujeito e predicado:

(2) Amar a Deus é essencial para a felicidade do ser humano.

(sujeito - oração subordinada substantiva subjetiva)

(3) A Bíblia nos ensina a amar a Deus sobre todas as coisas.

(objeto indireto - oração subordinada objetiva indireta)

(4) Sem amar a Deus, o homem perde o sentido da vida.

(advérbio - oração subordinada adverbial condicional)

(5) Aquela não era uma pessoa de amar a Deus.

(adjetivo - oração subordinada adjetiva)

Na composição das orações, fica mais claro de se visualizar que a oração reduzida de infinitivo (conforme a classificação da gramática normativa) amar a Deus desempenha a função de um sintagma nominal, prova disso é que ela assume funções nominais, de nome, no caso do sujeito e dos objetos direto e indireto, e de adjetivo, que também éforma nominal, tendo em vista que acompanha nomes e se comporta sintática e semanticamente como nome. Além disso, pode desempenhar a função de advérbio, que muitas vezes se comporta como adjetivo.

Para Paschoalin e Spadoto (1996), nem toda frase é uma oração e nem toda a oração é uma frase. Uma frase é independente semântica e sintaticamente, como Que dia bonito!,que é uma frase, mas não é uma oração, pois não tem verbo. Já no período (frase organizada por uma ou mais orações) Queremos que a justiça impere no Brasil, temos duas orações, pois temos dois verbos, mas que não fazem sentido isoladamente, ou seja, para se formar a frase são necessárias as duas orações, já que uma é complemento da outra (a segunda oração corresponde ao objeto direto da primeira).

Santana (2012) discute em artigo como o letramento e as práticas sociais e discursivas do indivíduo devem ser consideradas no estabelecimento de diagnóstico e terapêutica da Demência de Alzheimer. Ela pondera que as habilidades cognitivas e linguísticas não devem ser analisadas de forma desvinculada da história e vicissitudes do sujeito, sob o risco de que qualquer déficit no processamento e compreensão da fala e da escrita seja interpretado como uma deficiência no funcionamento cerebral. Entre os testes usados para se estabelecer a Demência de Alzheimer, encontra-se o Miniexame do Estado Mental. Para a autora "esses testes enfocam prioritariamente aspectos metalinguísticos e são construídos para o diagnóstico de afasia que são resultantes de lesões focais".

Damasceno (1999) pontua que os testes que têm sido usados para analisar a linguagem de idosos, saudáveis ou com algum tipo de demência, são metalinguísticos,portanto, privilegiam os níveis estruturais da língua, fonologia, sintaxe e semântica. Os níveis discursivo e pragmático são deixados de lado. Como os testes não contemplam aspectos discursivos e epilinguísticos, deixam de detectar 
precocemente perturbações no processo de significação, como as alterações nas relações de sentido, problemas com pressuposição, violação de leis conversacionais, dificuldades com operadores e argumentos, com o acesso e a manutenção de tópicos, além de problemas nos mecanismos de coerência e coesão textual.

Entretanto, será que os falantes em geral da língua portuguesa têm em mente questões de metalinguagem quando lhes é solicitado que produzam uma frase? Provavelmente, a maioria dos falantes, mesmo tendo sido expostos a essas regras na vida escolar, não tenham muita familiaridade com esses conceitos, até porque há dúvidas e divergências mesmo entre gramáticos e linguistas. Veremos, na seção seguinte, que algumas teorias linguísticas oferecem uma explicação plausível para a intuição linguística que pode estar subjacente em se considerar amar a Deus uma frase. Isso mostra que a resposta da paciente não pode ser considerada um erro.

\subsection{Evento, predicação e frames: qual é a} estrutura de uma frase

Segundo a teoria da Semântica de Eventos ${ }^{1}$ (DAVIDSON, 1967; PARSONS, 1990), há uma relação semântica entre um evento e sua nominalização.

Ocorre que nominalizações de eventos denotam eventos. Quando uma nominalização de evento é argumento de um verbo perceptual, é possível visualizar melhor a sua contribuição semântica. Por exemplo, considere a relação entre as frases abaixo:

(6a) Ágata viu Brutus ferir César.

\footnotetext{
${ }^{1}$ A Semântica de Eventos é uma teoria criada por Davidson (1967), e posteriormente incrementada e aperfeiçoada por Parsons (1990), que institui um argumento de evento na forma lógica de uma sentença. Por exemplo, para a sentença Brutus feriu César, teríamos a seguinte forma lógica, sendo que cul (culminância) refere-se ao aspecto da sentença (perfectivo): $(\exists$ e) [Ferir (e) \&Cul (e) \& Agente (e, Brutus) \& Tema (e, César)]. Em Martins (2012), encontramos uma explicação detalhada dessa teoria.
}

(6b) Ágata viu o ferimento de César por Brutus.

De acordo com a Semântica de Eventos, é possível explicar que se está falando, em (6 $\left.6^{\underline{a}}\right)$ e (6b), de um mesmo evento, o evento de ferimento cujo agente é Brutus e o paciente é César, na primeira sentença numa construção verbal ativa e na segunda numa construção com nominalização.

Nas sentenças perceptuais, como em (6), por causa do verbo "ver", também encontramos mais um argumento a favor da materialização de um argumento de evento, isto é, de se enriquecer a ontologia com mais um indivíduo. Trata-se do fato de que se Ágata viu algo, esse algo deve existir, deve ter uma referência. $O$ que é que Ágata viu? Aparentemente ela viu uma ação. Nesse caso, a referência é um evento. Além disso, é clara a menção que fazemos a eventos em certas sentenças, como:

(7) Depois de cantar o hino, eles saudaram a bandeira

Na sentença (7), no sintagma 'cantar o hino', há uma referência explícita a uma ação, a ação ou evento de cantar o hino, disso se pode pensar que estamos falando de um evento e, portanto, assumese a existência de um evento. Desse exemplo, também podemos extrair as relações entre o verbo conjugado e os nomes deverbais - infinitivo, gerúndio e particípio -, que serão representados da mesma forma, já que independentemente de sua manifestação linguística, todos eles denotam uma mesma entidade, o evento.

Sendo assim, poderíamos projetar a seguinte sentença:

(8) Depois de amar a Deus, os fiéis comungaram o corpo de Cristo.

Além do fato de uma nominalização poder denotar um evento, existe a questão da alternância sintática. O contexto gramatical de uma sentença varia muito. Os verbos podem mudar de valência, 
inclusive deixando de atribuir papéis temáticos e deixando de ser acusativos para serem inacusativos (JACKENDOFF, 1990; PINKER, 2008; LEVIN E HOVAV, 1995).

(9) Maria cozinhou o feijão.

(10) O feijão cozinhou bem.

Será que uma sentença com a estrutura de (10), por não apresentar objeto, pois o verbo passou a ser inacusativo, seria considerada um erro e não pontuaria no Miniexame do Estado Mental?

$\mathrm{Na}$ perspectiva da Semântica Denotacional, Frege (1978) propõe que toda e qualquer sentença é composta de predicado e argumentos. Para Frege, o conceito de predicado, diferentemente daquele da gramática tradicional que opõe sujeito e predicado, é uma estrutura não saturada, com lacunas, que prevê a possibilidade de preenchimentos alternativos. São, portanto, estruturas incompletas que se completam com argumentos. Esses argumentos são expressões, por sua vez, já saturadas, do tipo nomes próprios, descrições definidas ou até mesmo sentenças, pois elas compõem períodos por subordinação ou coordenação (na nomenclatura da gramática tradicional), ou por encaixamento (conforme a Teoria Gerativa).

No caso aqui analisado, "Amar a Deus", uma oração reduzida de infinitivo, conforme a gramática gerativa, não é um predicado saturado. Um predicado saturado é uma proposição passível de verificação de verdade, pois possui sentido e referência. Contudo, isso não se aplica a "Amar a Deus", tendo em vista que não há telicidade, ou seja, o tempo não está delimitado, pois está no infinitivo. Assim não é possível de se analisar o conteúdo verifuncional da sentença sem a referência de tempo. Nesse caso, de um ponto de vista formalista, "amar a Deus" não é uma sentença completa. Aparentemente, o Miniexame do Estado Mental, ao não considerar "amar a Deus" como uma frase, adota um ponto de vista puramente formal.

No entanto, numa abordagem diferente da gerativa, Talmy (2003) e Jackendoff (1983) defendem que, além das estruturas sintáticas, deve haver também estruturas semânticas, que formatam a nossa interpretação de sentenças. Dessa forma, a linguagem não seria um módulo separado e independente, mas estaria interligada com os outros aspectos cognitivos. Assim, a linguagem apresenta relação com outros sistemas cognitivos, como a visão, por exemplo. Assim, estruturas visuais como a oposição FIGURA/FUNDO são também relevantes para a linguagem.

É um posicionamento de vários outros estudiosos, que se "afastam do gerativismo ao postularem a continuidade entre a linguagem e as demais capacidades cognitivas". (SALOMÃO, 2009).

Os Modelos Cognitivos Idealizados (ICM) ou Frames estão conectados com os "tijolinhos" da percepção humana: FIGURA, FUNDO, TRAJETÓRIA e MOVIMENTO. Esses são os elementos mínimos de significado, especificamente, para nossa representação de espaço e movimento. O ser humano possui a habilidade cognitiva da seleção, ou seja, a capacidade de se focar em determinada parte do que se experiencia e no que se acha que é relevante naquele momento. Da mesma forma, temos a capacidade de ignorar aspectos do que experienciamos e que consideramos não relevantes. "Atenção e saliência" (CROFT e CRUSE, 2009), responsáveis pela seleção, são capacidades cognitivas que estão diretamente relacionadas à seleção. Para Pinker (2008),

[...] dependendo de como descrevemos um evento mentalmente para nós mesmos, o que por sua vez depende de no que escolhemos nos concentrar e ignorar e a capacidade de enquadrar um fato de formas autoexcludentes [...] é também uma fonte da riqueza da vida intelectual humana. (PINKER, 2008, p. 17).

\section{Situando o Miniexame Mental na perspectiva da linguística cognitiva}

Uma das capacidades cognitivas medidas no Miniexame Mental é a memória de fixação, que consiste em avaliar como está a capacidade de o paciente "saber" nominar objetos concretos. Isso quer dizer que ele precisa ter uma memória lexical. 
No teste analisado aqui, o investigador fala três palavras para a paciente - "vaso", "carro" e "tijolo" -, adverte que ela deve prestar atenção, pois depois terá de lembrar-se delas, e repetir logo na sequência. Assim que o investigador acaba de falar as três palavras, pede para a paciente repeti-las, mas ela profere: "vaso", "carro" e "muro", e repete "muro". O investigador então a corrige: "Não é muro. Preste atenção, carro, vaso e tijolo."

Então ele faz outras duas perguntas, mostrando à paciente dois objetos e solicitando que ela diga os nomes dos objetos, o que ela responde corretamente. Em seguida, o investigador faz com que ela repita uma frase, para testar sua fluência na articulação dos fonemas. E então ele pede que ela diga novamente as três palavras que foram dadas para memorização. A paciente responde "vaso" e "tijolo", e comenta que não está conseguindo se lembrar bem das palavras. Nota-se que ela esqueceu-se da palavra "carro".

É interessante ressaltar que, na primeira vez em que ela foi solicitada para repetir as palavras, ela não substituiu a palavra que ela não se lembrou por outra qualquer, mas a palavra que ela pôs no lugar foi uma palavra com significado próximo da outra. Ora, "tijolo" e "muro" não são duas coisas completamente estranhas uma a outra, muito pelo contrário, um muro geralmente é feito com uma junção de tijolos empilhados e unidos por uma massa composta de cimento, areia e água.

Quando é solicitado, depois de algumas outras perguntas, que ela diga as mesmas palavras fornecidas pelo investigador, na etapa de análise da memória de evocação, ela então se esquece da palavra "carro", que não tem o mesmo material de que é feito o vaso e o tijolo - a argila -, e retoma somente as duas palavras que ela conseguiu relacionar, pois elas têm mesmo uma relação, vaso e tijolo.

De acordo com Croft e Cruse (2009), as experiências do ser humano têm efeito no modo de conhecimento do mundo. O que é vivido inclui os fatores contextuais, as inferências e a percepção. Assim, também acompanha a linguagem: memórias de longo e curto prazo, ativação de fluxo de eventos (streamofevents).

Um exemplo de como se dá essa dinâmica em relação à ativação de memória é quando alguém está falando de sapo e, logo em seguida, fala em brejo. É natural, há uma sequência de assunto, vocabulário e, consequentemente de frames. É uma extensão natural, continua-se no mesmo campo semântico. Todavia, se o assunto é sobre sapo e alguém fala sobre comida, há um estranhamento inicial, pois acontece uma quebra do fluxo conversacional, que vai se dissipar no momento em que novos frames sejam acionados.

Tendo-se em vista que o envelhecimento afeta principalmente a memória e a evocação livre e retardada de material verbal aprendido, preservando sua lembrança baseada em pistas contextuais, como, por exemplo, de imagens visuais, poder-se-ia considerar que as palavras muro, tijolo e vaso estão em um fluxo de eventos e que, portanto, seriam mais naturalmente relacionadas, consequentemente a evocação seria mais fácil.

Dois conceitos semânticos que também poderiam ser testados nessa análise seriam os de hiperonímia e hiponímia. A hiperonímia indica um nível mais amplo de categorização; já a hiponímia indica uma categorização de nível mais básico, que é parte da categorização hiperonímica. Por exemplo: animal de estimação é um hiperônimo de gato; de forma reversa, gato é um hipônimo de animal de estimação.

No caso da palavra "muro", que foi evocada equivocadamente no lugar da palavra "tijolo", é possível se pensar numa espécie de zoom mental, um enquadre (PINKER, 2008), em que o "tijolo" está num zoom mais aproximado e "muro" numa cena mais aberta.

\section{Conclusão}

Analisando duas questões que envolvem a linguagem em uma aplicação do Miniexame do Estado Mental, conclui-se que o que foi considerado como "erro", pode ser muito significativo e indicar que 
a linguagem usada pelo pacientecarrega uma estrutura subjacente de acordo com a da maioria dos falantes da sua língua. Assim, ele pode estar bem perto do acerto, se, talvez, fosse o caso de se fazer uma escala de aproximação com o que seria 0 idealizado. Contudo, entende-se que, para os propósitos para os quais esse teste foi criado, seja exigida objetividade.

Este trabalho não ambicionou discutir a Demência de Alzheimer, tampouco questionar os métodos e instrumentos usados para auxiliar no diagnóstico dessa patologia. É sabido que o Miniexame do Estado Mental testa as capacidades e habilidades cognitivas, como atenção e cálculo, orientação espacial e temporal e capacidade construtiva, além da linguagem e memória. Mesmo que a linguagem seja avaliada especificamente em apenas uma seção do teste, o fato de que a linguagem (verbal prioritariamente) é um modo fundamental para se definir as habilidades cognitivas de uma pessoa, a análise da performance verbal deve ser cuidadosamente escrutinada. De acordo com a Linguística Cognitiva, a linguagem é uma capacidade cognitiva que está vinculada a todas as outras, interagindo com elas e permeando as suas manifestações.

Ao se considerar a linguagem como um aspecto cognitivo que interage com os outros, abre-se um campo de pesquisas e discussões - que poderia ser explorado numa parceria entre Linguística e Neurologia, por exemplo, bem como demais áreas da saúde que pesquisam e tratam de patologias mentais.

\section{Referências}

BECHARA, Evanildo. Moderna Gramática Portuguesa. Rio de Janeiro: Lucerda, 2003.

BRASIL (MINISTÉRIO DA EDUCAÇÃO). Parâmetros Curriculares Nacionais: Língua Portuguesa. Brasília, $1997 . \quad$ Disponível em: http://portal.mec.gov.br/seb/arquivos/pdf/livro02.pdf Acesso em: 25 fev. 2014.

CROFT, W. \& CRUSE, D. A. Cognitive Semantics.Cambridge, Cambridge University Press, 2009.
CRUZ, F. M. Uma perspectiva enunciativa das relações entre linguagem e memória no campo da neurolinguística. (Dissertação de Mestrado). Campinas: UNICAMP/IEL, 2004. Disponível em: http://www.iel.unicamp.br/projetos/cogites/pdf/td cruz 01.pdf Acesso em: 10 jan. 2014.

DAMASCENO, B. P. Envelhecimento cerebral: o problema dos limites entre o normal

e o patológico. In: Arq. Neuro-Psiquiatr., São Paulo, v. 57, n.1, p.78-83, 1999. Disponível em: http://www.scielo.br/scielo.php?script=sci arttext\&pid =S0004-282X1999000100015 Acesso em: 20 fev. 2014.

DAVIDSON, Donald. The Logical Form of Action Sentences. In The Logic of Decision andAction.81-95. Pittsburgh: Universityof Pittsburgh Press, 1967.

FREGE, G. Sobre o sentido e a referência. Lógica e filosofia da linguagem.São Paulo: Cultrix, 1978.

JACKENDOFF, R. Semantics and Cognition. Cambridge, MA: MIT Press, 1983.

JACKENDOFF, R. Semantic Structures. Cambridge (Mass.): MIT Press, 1990.

LEVIN, B.; HOVAV, M. Unaccusativity.Cambridge, (Mass.): MIT Press, 1995.

MARTINS, D. D. Uma análise do conceito de cumulatividade. (Dissertação de Mestrado). Florianópolis: Universidade Federal de Santa Catarina, 2012.

PARSONS, Terence. Events in the semantics of English: A study in the subatomic semantics. Cambridge: MIT Press, 1990.

PASCHOALIN, M. A. Gramática: teoria e exercícios. São Paulo: FTD, 1996.

PINKER, S. Do que é feito o pensamento: a língua como janela para a natureza humana. Trad. de Fernanda Ravagnani. São Paulo: Companhia das Letras, 2008.

SANTANA, A. P. Letramento e Demência de Alzheimer. In: MOURA, H.; MOTA, M. B.; SANTANA, A. P. (Orgs.). Cognição, Léxico e Gramática. Florianópolis: Insular, 2012.

SALOMÃO, M. M. M. FrameNet Brasil: um trabalho em progresso. In: Calidoscópio, v. 7, n. 3, p. 171-182, set./dez. 2009. Unisinos.

TALMY, L. Toward a Cognitive Semantics: Typology and Process in Concept Structuring. Volume II. Cambridge, MA: MIT Press, 2003. 